\title{
Cyclic creep behaviour of two-phase Ti-6Al-2Mo-2Cr alloy
}

\author{
Waldemar Ziaja ${ }^{a, b *}$, Maciej Motyka ${ }^{a, b}, K$ rzysztof Kubiak ${ }^{a, b}$, Jan Sieniawski ${ }^{a, b}$ \\ ${ }^{a}$ Department of Materials Science, Rzeszow University of Technology, Al. Powstancow Warszawy 12, 35-959 Rzeszow, Poland \\ ${ }^{b}$ R\&D Laboratory for Aerospace Materials, Rzeszow University of Technology, ul. Zwirki i Wigury 4, 35-959 Rzeszow, Poland \\ *wziaja@prz.edu.pl
}

\begin{abstract}
$\underline{\text { Abstract }}$
One of the important criteria for selection titanium alloys for discs and blades of turbine engine compressor is their fatigue and creep strength at room and elevated temperature. Fatigue and creep properties of two-phase titanium alloys show strong dependence on microstructure, especially morphology of the $\alpha$ and $\beta$ phases which can be controlled to certain extent by proper selection of hot working and heat treatment conditions. Quantitative description of two-phase titanium alloys behaviour under loading and environmental conditions leading to combined creep and fatigue processes has been always very challenging task due to large number of factors affecting deformation and fracture behaviour of the material.

In the course of the research cyclic creep behaviour of Ti-6Al-2Mo-2Cr alloy (VT3-1) was investigated and compared to low-cycle fatigue and static creep properties at the temperature of $450{ }^{\circ} \mathrm{C}$. Microstructure of the alloy was varied by means of the heat treatment. Constant load tensile creep tests were carried out. Tension-tension cyclic loading was applied at the constant stress ratio with and without hold time at maximum load. The effect of test parameters on the creep-fatigue life at elevated temperature was estimated. Characteristic features of fracture surfaces were identified by scanning electron microscopy methods.
\end{abstract}

\section{Introduction}

There has been still growing demand for titanium alloys over the last decades. It stems from the combination of their advantageous properties like high specific strength at room and elevated temperature, fracture toughness and corrosion resistance which makes them the important structural material in chemical, energy and aerospace industries [1-3]. These properties accompanied by biocompatibility of titanium are also the reasons for growing number of applications in biotechnology [4].

In the case of discs and blades in compressor section of the turbine aero engines near- $\alpha$ and two-phase $\alpha+\beta$ alloys are predominantly used, for which maximum operational temperature reaches about $650^{\circ} \mathrm{C}$ and $450^{\circ} \mathrm{C}$ respectively. In this kind of applications fatigue and creep strength criteria at room and elevated temperature are of primary importance in the material selection process [5]. Operation of cyclic loads at elevated temperature leads to synergetic effect of fatigue and creep processes leading to increase in damage accumulation rate [6].

Titanium and its alloys are prone to development of large time dependent strains even for stresses significantly lower than yield strength and temperature below $0,25 T_{\mathrm{m}}$. In some cases transient creep strains were observed at room temperature both in CP titanium and titanium alloys [7-9]. This phenomenon is disadvantageous in the case of elements operating under dwell fatigue conditions when it can lead to premature failure. Sensitivity of titanium alloys to load hold periods at peak stresses was reported both for room and elevated temperature fatigue regime [10-12].

Mechanical properties of titanium alloys can be optimized by control of the morphological parameters of microstructure like the size, shape and distribution of the grains of various phases, texture, structure and strength of grain boundaries and others. Fatigue and creep properties of two-phase titanium alloys show strong dependence on microstructure, especially morphology of the $\alpha$ and $\beta$ phases which is usually developed in the processes of hot working and heat treatment. Important issue is the extent to which the microstructure of two-phase titanium alloys affects the creep-fatigue interactions. According to several studies aligned $\alpha$ microstructure formed by slow cooling from above $\beta$ transus temperature is particularly susceptible to dwell sensitive fatigue due to favourable conditions for propagation of small cracks through the $\alpha$ phase lamellae [13-15].

One of the possible reasons of dwell sensitivity of titanium alloys is stress redistribution between relatively week and strong grains in the alloy which occurs in the case of rate dependence of the material, even at temperatures considered low for creep. Weak $\alpha$ grains are these with basal plane at certain angle to the tensile axis and strong areas include those in which the basal planes are perpendicular to the tensile axis. The slip on weak grains piles up at the boundary with a neighbouring strong grain. The

(C) The Authors, published by EDP Sciences. This is an open access article distributed under the terms of the Creative Commons Attribution License 4.0 (http://creativecommons.org/licenses/by/4.0/). 
pile-up generates the required combination of shear and tensile stresses on the unfavourably oriented basal plane, which induces facet formation in alliance with the applied principal stress [13]. The magnitude of the induced stress is proportional to the length of the dislocation pile-up and hence the grain size. The alloys in which the primary $\alpha$-phase grains are broken up by heat treatment are usually less dwell sensitive. Cleavage or quasi-cleavage facets are typical features of the fracture surface of $\alpha+\beta$ titanium alloys in the creep-fatigue regime, especially in the lower temperature range. The facets typically have a basal plane orientation $[16,17]$.

\section{Materials and experiments}

The material studied was two-phase titanium alloy Ti-6Al-2Mo-2Cr, developed in Russia and known under the designation VT3-1, having following chemical composition (wt.\%): Al - 6.2, Mo - 1.96, $\mathrm{Cr}-2.07, \mathrm{Fe}-0.12, \mathrm{C}-0.08, \mathrm{Ti}-$ balance. This is martensitic $\alpha+\beta$ alloy which is characterized by high strength at room and elevated temperature and high fracture toughness. As a result of careful selection of heat treatment conditions high creep resistance of the alloy can also be obtained at the temperature up to $450^{\circ} \mathrm{C}[2,18]$. The alloy was delivered in the form of rolled bars, $16 \mathrm{~mm}$ in diameter in mill-annealed condition. In order to determine the influence of basic morphological features of the microstructure on the high temperature properties of the alloy two distinct schemes of heat treatment process were applied.

As a result of annealing at the temperature above $\beta$ transus $\left(1000^{\circ} \mathrm{C}\right)$ followed by controlled cooling at the rate of $0.06^{\circ} \mathrm{C}$ $\mathrm{s}^{-1}$ typical lamellar microstructure was developed, consisting of $\alpha$-phase plates layered with $\beta$ phase (Fig. 1a). Annealing at the temperature in $\alpha+\beta \rightarrow \beta$ phase transformation range $\left(930^{\circ} \mathrm{C}\right)$ followed by air cooling led to formation of globular morphology of stable $\alpha$ and $\beta$ phases (Fig. 1b).

Microstructure of the alloy was examined using light microscope Nikon Epiphot 3 equipped with DS-1 camera. Average values of selected quantitative parameters of the microstructure were determined using image analysis software Aphelion v.2.3. For the lamellar microstructure diameter of primary $\beta$ phase grains $\left(d_{\beta}\right)$, diameter of the colonies of $\alpha$ phase lamellae $\left(d_{\mathrm{c}}\right)$ and thickness of $\alpha$ lamellae $\left(t_{\alpha}\right)$ were measured while for globular microstructure grain size $\left(d_{\alpha}\right)$ and volume fraction $\left(v_{\alpha}\right)$ of $\alpha$ phase were determined.

a)

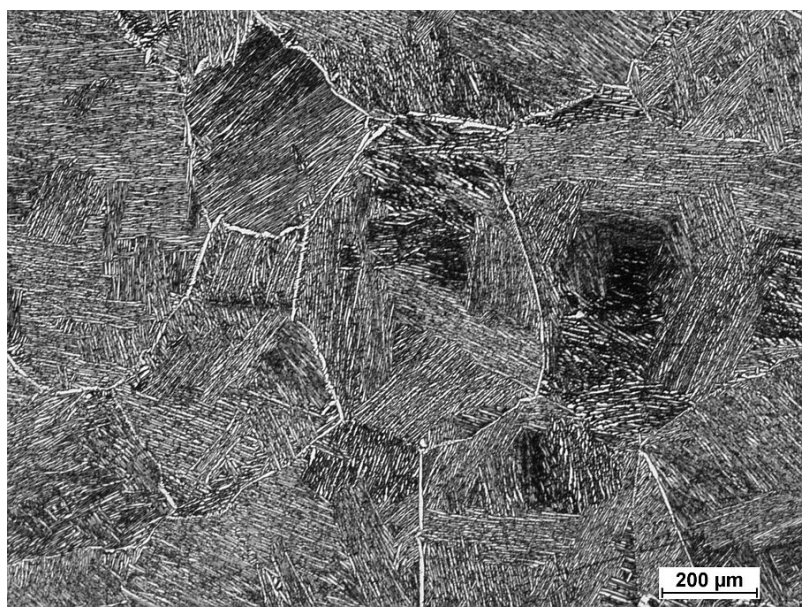

b)

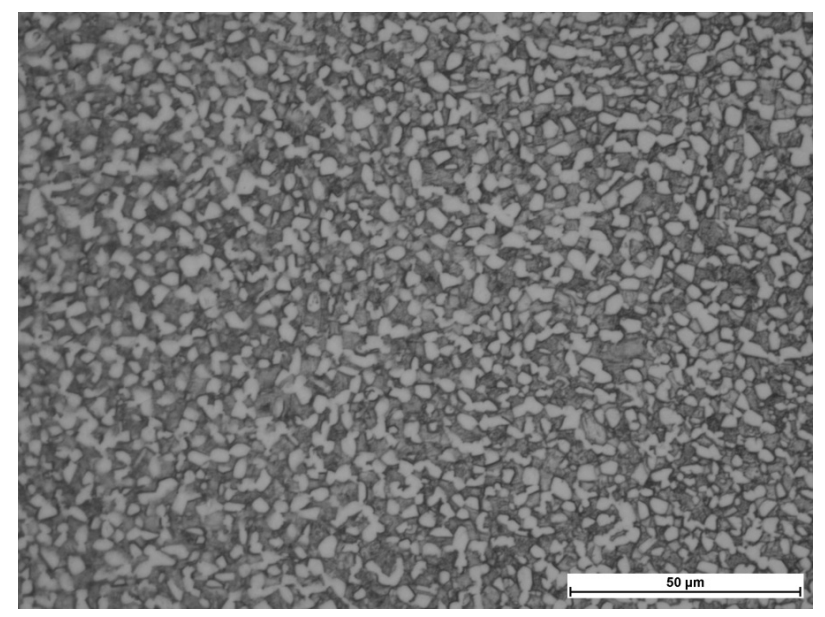

Fig. 1. Microstructure of two-phase Ti-6Al-2Mo-2Cr alloy: a) lamellar, b) globular.

Static tensile tests were carried out at the temperature of $450^{\circ} \mathrm{C}$ on testing machine Instron 5982 at the constant strain rate of $0.005 \mathrm{~min}^{-1}$. The strain was measured during the test by extensometer with $1 \mu \mathrm{m}$ resolution. Constant load creep tests were carried out at the temperature of $450^{\circ} \mathrm{C}$ in air on Walter+Bai AG LFMZ-30kN electromechanical creep machines.

Stress controlled fatigue and cyclic creep tests were performed at the temperature of $450^{\circ} \mathrm{C}$ on Instron 8801 servohydraulic testing machine, in tensile mode at the load ratio $\mathrm{R}=0.1$. Loading and unloading ramps were realised at the constant time of $5 \mathrm{~s}$ (in both cases). Hold time at peak stress equal $120 \mathrm{~s}$ was applied in cyclic creep tests. In all tests smooth, cylindrical specimens were used, with a gauge diameter and gauge length of 6 and $24 \mathrm{~mm}$ respectively.

Fracture surfaces of selected specimens were examined using Hitachi S3400 scanning electron microscope.

\section{$\underline{\text { 3. Results and discussion }}$}


Annealing above $\beta$-transus resulted in significant growth of primary $\beta$-phase grains $\left(d_{\beta}=430 \mu \mathrm{m}\right)$. Slow, controlled cooling led to formation of $\alpha$-phase in the shape of parallel lamellae of the average thickness $t_{\alpha}=2.1 \mu \mathrm{m}$ arranged in colonies having average diameter $d_{\mathrm{c}}=48 \mu \mathrm{m}$.

In the alloy with globular microstructure obtained by air cooling from the temperature in $\alpha+\beta \rightarrow \beta$ phase transformation range insignificant grain growth was noticed comparing to initial microstructure, and the average values of morphological parameters of $\alpha$ phase were equal: $d_{\alpha}=3.5 \mu \mathrm{m}, V_{\alpha}=62 \%$.

Tensile properties at $450^{\circ} \mathrm{C}$ of the alloy with various microstructure differed in terms of yield strength and ultimate tensile strength which were equal $\mathrm{YS}_{\mathrm{g}}=643 \mathrm{MPa}, \mathrm{UTS}_{\mathrm{g}}=802 \mathrm{MPa}$ and $\mathrm{YS}_{1}=585 \mathrm{MPa}, \mathrm{UTS}_{1}=754 \mathrm{MPa}$ for globular and lamellar microstructure respectively (mean values from three tests).

Morphology of the microstructure showed noticeable impact on the elevated temperature low-cycle fatigue behaviour of the alloy with respect to its sensitivity to load holds. In the case of the alloy with globular microstructure fatigue life reduction due to load hold periods in relation to the pure cyclic data was found to be stress dependant. This effect was more evident at relatively high stresses (Fig. 2a). The alloy with lamellar microstructure showed more pronounced dwell effect at all values of cyclic stress amplitude (Fig. 2b). The difference in load holds sensitivity is more clearly noticeable when the cyclic creep data are plotted against normalized stress value (the maximum applied cyclic stress divided by yield strength) to allow for variation in tensile properties of the two variants of the alloy (Fig. 3). It was found that fatigue life data for the alloy with lamellar and globular microstructure superimposed when plotted against normalized stress.

a)

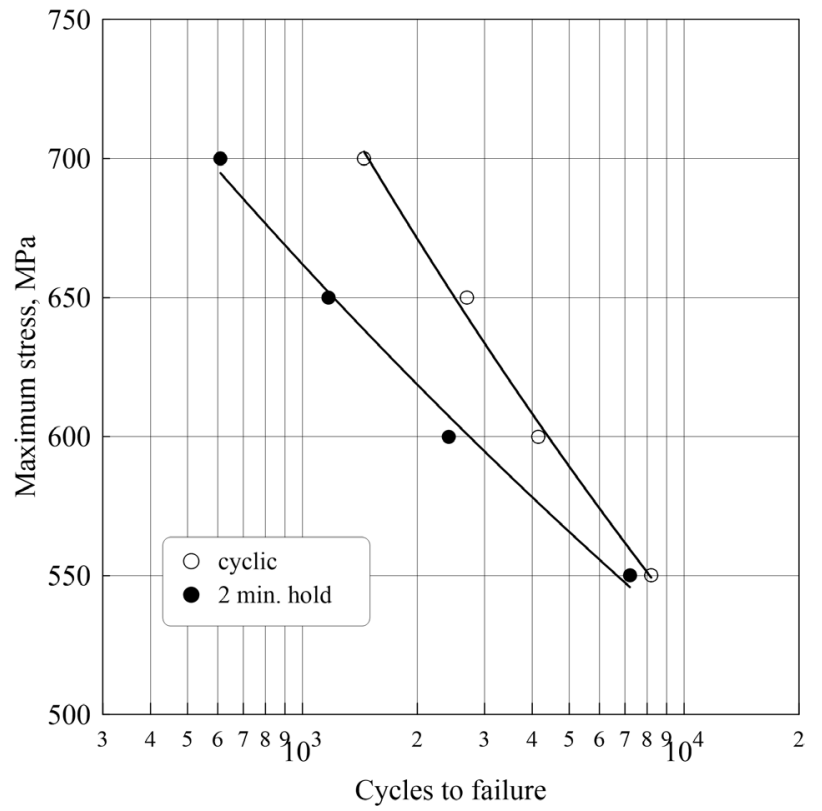

b)

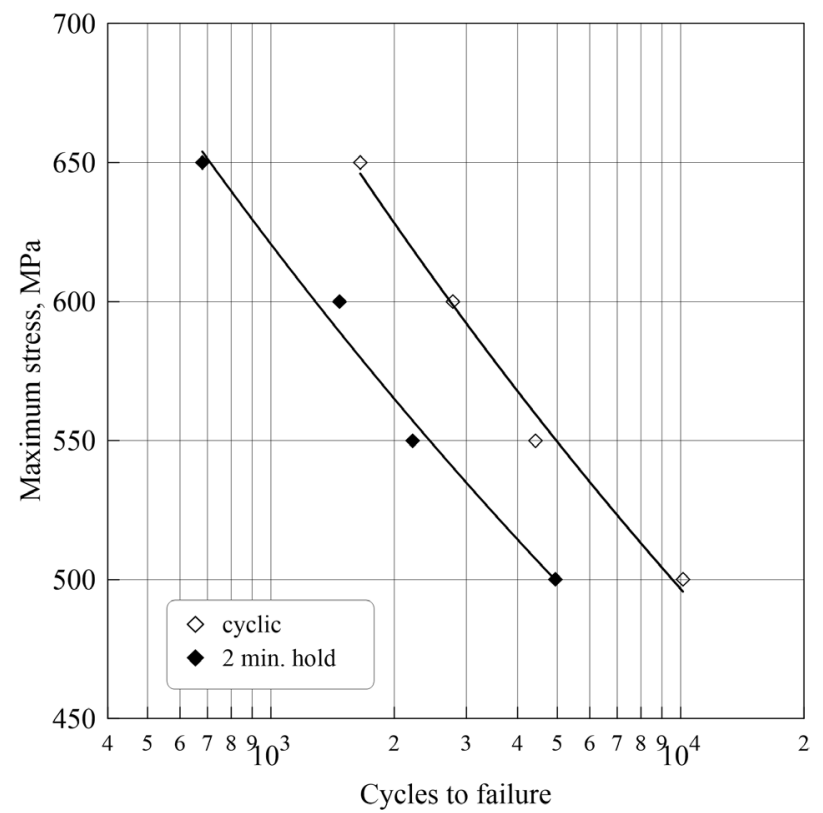

Fig. 2. Cyclic life of Ti-6Al-2Mo-2Cr alloy at $450^{\circ} \mathrm{C}$ : a) globular, b) lamellar microstructure

Analysis of the results of constant load creep tests revealed that the alloy with lamellar microstructure exhibited shorter life at the certain stress level, but for similar values of the normalized stress its creep resistance was superior comparing to alloy with globular microstructure (Fig. 4) in terms of longer creep life and smaller creep strain and strain rate of steady state creep.

For cyclic creep tests total time of load holds at maximum stress level was calculated and compared to the creep life of the material obtained at the same stress to evaluate the impact of cyclic stress changes imposed in cyclic creep test. For both variants of the alloy detrimental effect of load cycling on material life was identified (Fig. 5). However its intensity was stress dependant and increased with decreasing value of maximum stress in load cycle. 


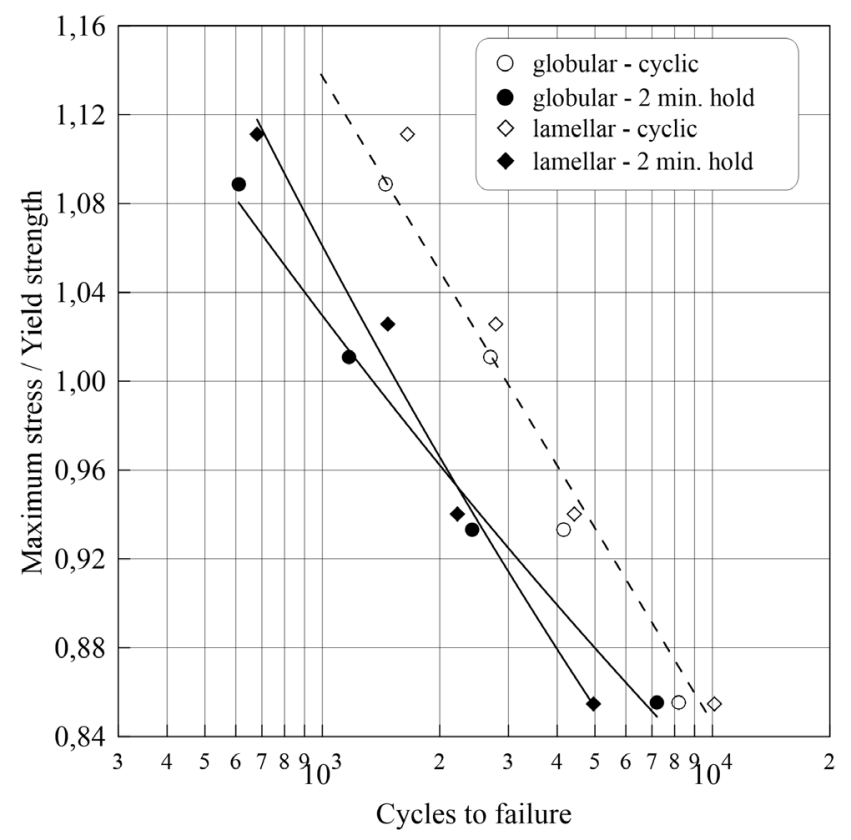

Fig. 3. Cyclic life of Ti-6Al-2Mo-2Cr alloy at $450^{\circ} \mathrm{C}$ against normalised stress.

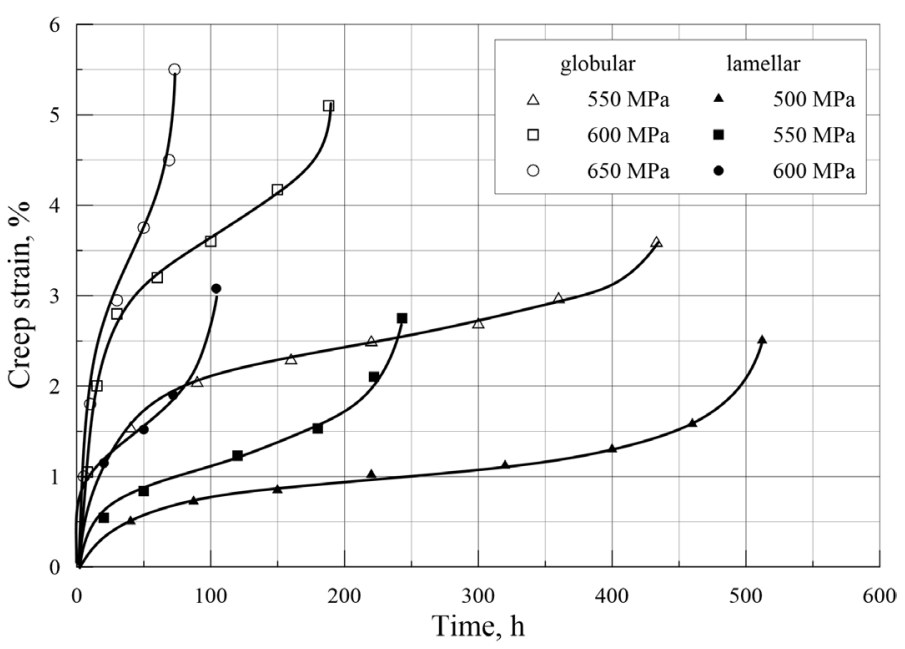

Fig. 4. Creep curves of Ti-6Al-2Mo-2Cr alloy at $450^{\circ} \mathrm{C}$.

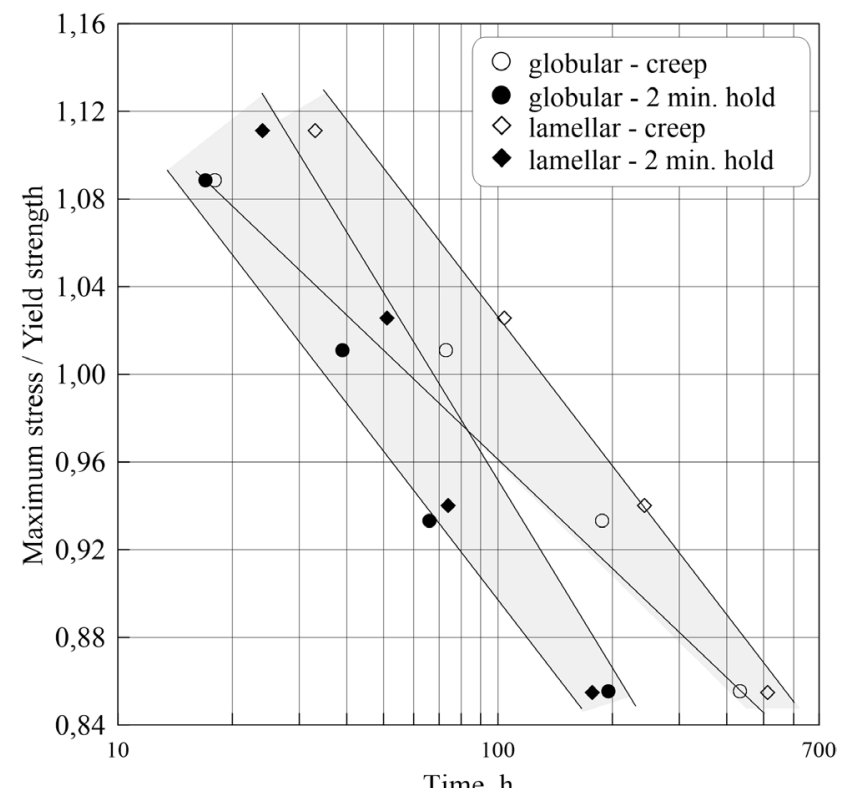

Fig. 5. Constant load and cyclic creep life of Ti-6Al-2Mo-2Cr alloy at $450^{\circ} \mathrm{C}$ against normalised stress 
SEM examination of the fracture surfaces after cyclic creep tests showed that the crack path was predominantly transcrystalline. Commonly observed creep phenomena as the formation of cavities or grain boundary sliding were not found. Furthermore, no typical sites where the cracks initiated were found. However in most cases cracks were found to initiate internally which is rather characteristic of creep failure as opposed to fatigue cracks which usually initiate at the surface.

On the fracture surfaces the striations, secondary cracks and quasi-cleavage-like areas were found. Quasi-cleavage facets are more likely to nucleate in load cycles with stress hold rather than strain hold due to the effect of load shedding, when the stresses redistribute from soft, creeping grains to the hard grains to maintain force equilibrium. The facets were found predominantly in samples of the alloy with lamellar microstructure (Fig. 5). Although the thickness of the individual $\alpha$-phase lamellae is comparable with grain size of globular $\alpha$-phase, the factor facilitating the facets formation is the common crystallographic orientation of $\alpha$-lamellae within the colonies as the facets nucleate along basal planes orientated approximately perpendicularly to the loading direction.

a)

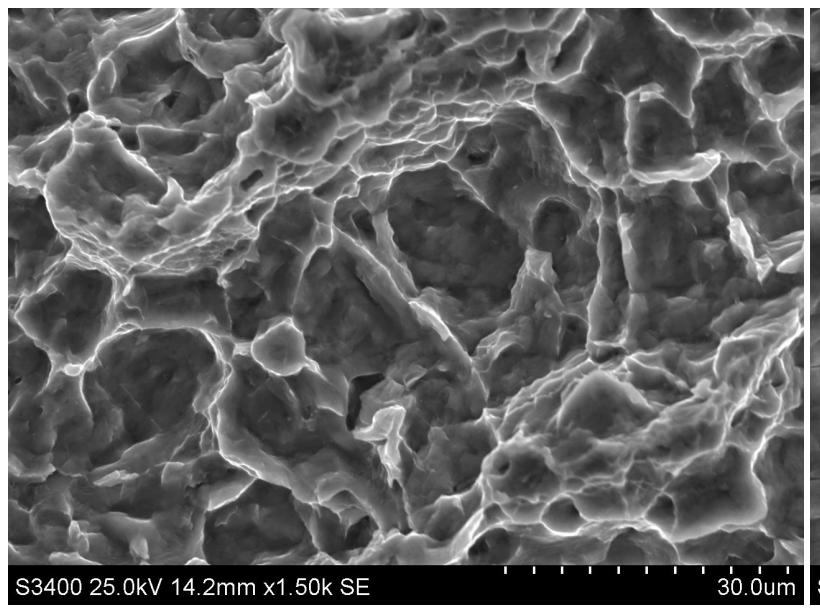

b)

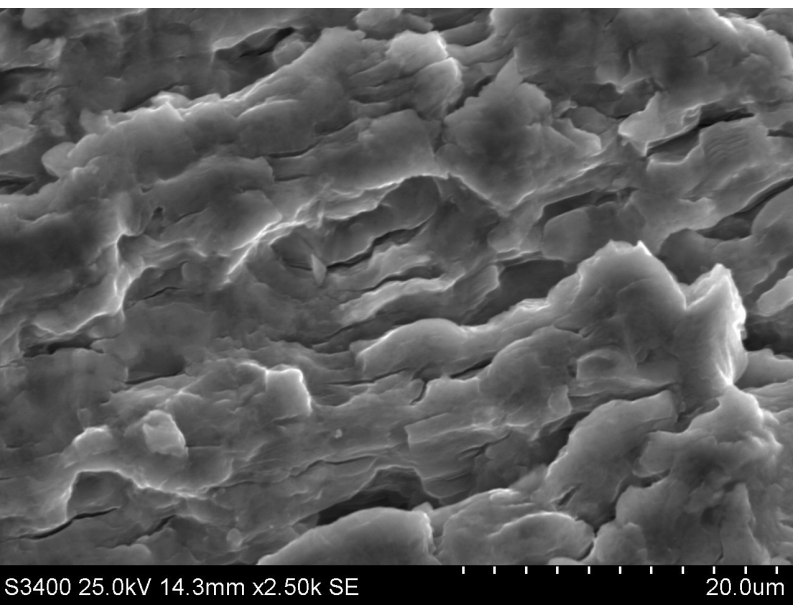

Fig. 6. Fracture surface of Ti-6Al-2Mo-2Cr alloy with globular microstructure after cyclic creep test. a) $\sigma_{\max }=700 \mathrm{MPa}$, b) $\sigma_{\max }=550 \mathrm{MPa}-$ dimples, fatigue striations and secondary cracks visible

a)

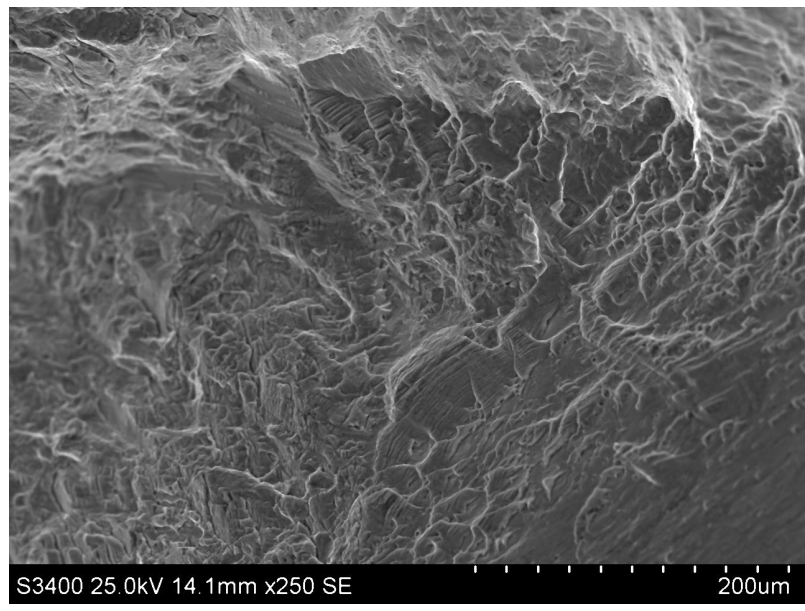

b)

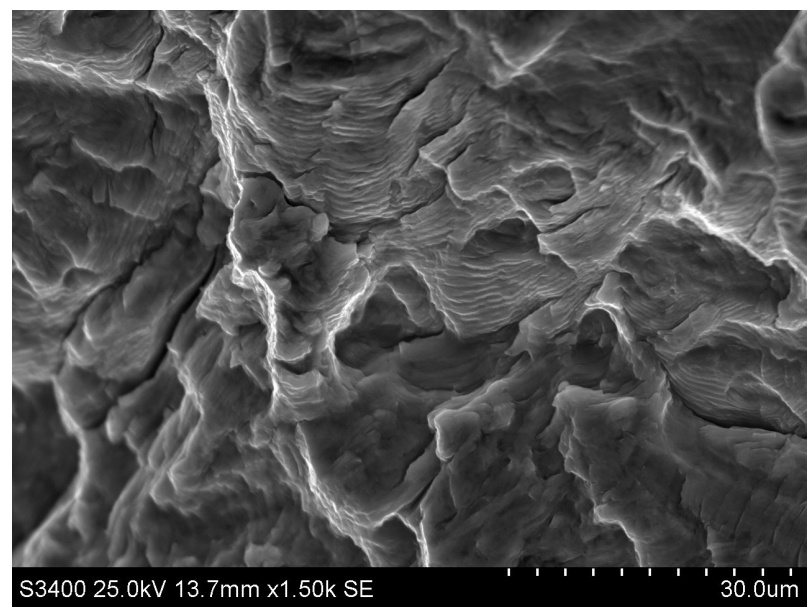

Fig. 7. Fracture surface of Ti-6Al-2Mo-2Cr alloy with lamellar microstructure after cyclic creep test. a) $\sigma_{\max }=550 \mathrm{MPa}$, b) $\sigma_{\max }=650 \mathrm{MPa}-$ quasi-cleavage-like areas, fatigue striations and secondary cracks visible.

\section{Summary}

Two-phase titanium alloy Ti-6Al-2Mo-2Cr with lamellar and globular microstructure was examined in constant load creep, low-cycle fatigue and cyclic creep tests at $450{ }^{\circ} \mathrm{C}$. On the basis of the analysis of the test results following findings were formulated: 
- $\quad$ Low-cycle fatigue life data for the alloy with lamellar and globular microstructure superimposed when plotted against normalized cyclic stress (maximum stress to yield strength ratio), showing no significant dependence on the microstructure.

- Load hold periods (120 s) in cyclic loading resulted in noticeable decrease in fatigue life of the alloy. The alloy with lamellar microstructure showed sensitivity to load hold periods at all stress levels applied. Sensitivity of fatigue life to load holds for the alloy with globular microstructure became smaller with decreasing value of the maximum stress in load cycle.

- Total time of the load holds in cyclic-creep test was found to be smaller than creep life determined in constant stress creep test for both variants of the alloy and each stress level applied. This effect was more evident in lower stress range.

- $\quad$ Fracture surfaces developed in all type of tests had transcrystalline character. The areas of ductile type fracture, especially in alloy with globular microstructure tested at high maximum stresses, were separated by quasi-cleavage-like areas. Secondary cracks were also observed which is characteristic for fatigue cracking of titanium alloys.

- $\quad$ Facets formation was facilitated in the alloy with microstructure consisting of aligned $\alpha$-lamellae sharing common crystallographic orientation. This resulted in more pronounced sensitivity of that variant of the alloy to load hold periods.

- The voids and wedge cracks were not observed on fracture surfaces after cyclic creep tests indicating that dislocation creep mechanism was a dominant mode of deformation at load hold periods.

\section{References}

[1] C. Leyens, M. Peters (eds): Titanium and Titanium Alloys. Wiley-VCH GmbH \& Co. KGaA, Weinheim 2003.

[2] G. Lütjering, J.C. Williams: Titanium. Springer, Berlin Heidelberg 2007

[3] R.R. Boyer, R.D. Briggs: The use of $\beta$ titanium alloys in the aerospace industry. Journal of Materials Engineering and Performance 14 (2005) 681-685.

[4] A.M. Khorasani et al.: Titanium in biomedical applications - properties and fabrication: a review. Journal of Biomaterials and Tissue Engineering 5 (2015) 593-619.

[5] J.S. Hewitt et al.: Titanium alloy developments for aeroengine fan systems. Materials Science and Technology 30 (2014) 1919-1925.

[6] T. Goswami: Low cycle fatigue - dwell effects and damage mechanisms. International Journal of Fatigue 21 (1999) 5576.

[7] M.F. Savage, T. Neeraj, M.J. Mills: Observations of room-temperature creep recovery in titanium alloys. Metallurgical and Materials Transactions 33A (2002) 891-898.

[8] J. Peng et al.: The temperature and stress dependent primary creep of CP-Ti at low and intermediate temperature. Materials Science \& Engineering A611 (2014) 123-135.

[9] W.J. Harrison, M.T. Whittaker, R.J. Lancaster: A model for time dependent strain accumulation and damage at low temperatures in Ti-6Al-4V. Materials Science \& Engineering A574 (2013) 130-136.

[10] P. Lefranc et al.: Nucleation of cracks from shear-induced cavities in an $\alpha / \beta$ titanium alloy in fatigue, room-temperature creep and dwell-fatigue. Acta Materialia 56 (2008) 4450-4457.

[11] M.R. Bache et al.: Crack growth in the creep-fatigue regime under constrained loading of thin sheet combustor alloys. International Journal of Fatigue 42 (2012) 82-87.

[12] J. Kumar, S.G.S. Raman, V. Kumar: Creep-fatigue interactions in Ti-6Al-4V alloy at ambient temperature. Trans Indian Inst Met 69 (2016) 349-352.

[13] M.R. Bache: A review of dwell sensitive fatigue in titanium alloys: the role of microstructure, texture and operating conditions. International Journal of Fatigue 25(2003) 1079-1087.

[14] W. Shen, A.B.O. Soboyejo, W.O. Soboyejo: Microstructural effects on fatigue and dwell fatigue crack growth in $\alpha / \beta$ Ti6Al-2Sn-4Zr-2Mo-0.1Si. Metallurgical and Materials Transactions 35A (2004) 163-187.

[15] W.J. Evans: Time dependent effects in fatigue of titanium and nickel alloys. Fatigue Fract. Engng Mater. Struct. 27 (2004) $543-557$. 
[16] F.P.E. Dunne, D. Rugg: On the mechanisms of fatigue facet nucleation in titanium alloys. Fatigue Fract. Engng Mater. Struct. 31 (2008) 949-958.

[17] S. Ankem et al.: Mechanical properties of alloys consisting of two ductile phases. Progress in Materials Science 51 (2006) 632709.

[18] G. Lütjering: Influence of processing on microstructure and mechanical properties of $(\alpha+\beta)$ titanium alloys. Materials Science \& Engineering A243 (1998) 32-45. 